CLINICAL STUDY

\title{
Cholic acid for hepatic steatosis in patients with lipodystrophy: a randomized, controlled trial
}

\author{
Zahid Ahmad $^{1,3}$, Lalitha Subramanyam ${ }^{1, \$}$, Lidia Szczepaniak ${ }^{3, \dagger}$, Vinaya Simha ${ }^{1, \S}$, Beverley Adams-Huet ${ }^{2,3}$ \\ and Abhimanyu Garg ${ }^{1,3}$ \\ ${ }^{1}$ Division of Nutrition and Metabolic Diseases, Center for Human Nutrition, ${ }^{2}$ Department of Clinical Sciences and ${ }^{3}$ Department of Internal Medicine, \\ UT Southwestern Medical Center, 5323 Harry Hines Boulevard, Dallas, Texas 75390, USA
}

(Correspondence should be addressed to A Garg at Division of Nutrition and Metabolic Diseases, Center for Human Nutrition, UT Southwestern Medical Center; Email: abhimanyu.garg@utsouthwestern.edu)

${ }^{\dagger}$ (L Szczepaniak is now at The Heart Institute, Cedars-Sinai Medical Center, Los Angeles, California, USA)

₹(L Subramanyam is now at North Texas Associates END, Irving, Texas, USA)

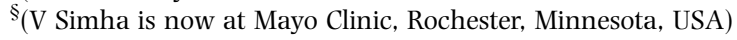

\begin{abstract}
Objective: Hepatic steatosis is a common complication in patients with lipodystrophies and can lead to cirrhosis. There is no proven effective therapy for hepatic steatosis, but cholic acid (CA), a farnesoid X receptor agonist, has previously been shown to reduce hepatic triglyceride (TG) content in mice and serum TG in humans. Our objective was to assess clinical efficacy and tolerability of CA therapy in patients with lipodystrophy and hepatic steatosis.

Design: A randomized, double-blind, placebo-controlled, crossover study.

Methods: Eighteen patients with genetic or autoimmune lipodystrophies and elevated hepatic TG content participated in the study. The intervention was CA (15 mg/kg per day) compared with placebo for a period of 6 months each. Hepatic TG content, the primary outcome variable, was measured with ${ }^{1} \mathrm{H}$ magnetic resonance spectroscopy at baseline and at 3 and 6 months during each study period. Levels of serum alanine aminotransferase (ALT), aspartate aminotransferase (AST), gamma-glutamyl transpeptidase (GGT), and TG were secondary end points of the study.

Results: Compared with placebo, CA did not reduce (median (interquartile range) hepatic TG content $(14.8 \%(9.4-19.0 \%)$ vs $15.9 \%(10.5-26.5 \%)$ respectively; $P=0.42)$ or serum TG $((340 \mathrm{mg} / \mathrm{dl}$ $(233-433 \mathrm{mg} / \mathrm{dl})$ vs $390 \mathrm{mg} / \mathrm{dl}(233-595 \mathrm{mg} / \mathrm{dl})$ respectively; $P=0.45))$. CA therapy also did not change AST, ALT, or GGT levels. Two patients developed diarrhea and excessive flatus while taking CA and these symptoms resolved after reducing the dose of CA.

Conclusion: CA was well tolerated but did not reduce hepatic TG content in patients with lipodystrophy.

European Journal of Endocrinology 168 771-778
\end{abstract}

\section{Introduction}

Lipodystrophies are rare disorders characterized by selective loss of adipose tissue (1) and predisposition to metabolic complications such as diabetes mellitus, hypertriglyceridemia, and hepatic steatosis. Hepatic steatosis is a common complication in patients with genetic or acquired lipodystrophies $(1,2)$. Both cirrhosis requiring hepatic transplantation (3) and hepatocellular carcinoma (2), possibly due to long-standing hepatic steatosis, have been reported in patients with lipodystrophies. We and others have previously reported that recombinant leptin therapy reduced liver size and hepatic steatosis in hypoleptinemic patients with lipodystrophies $(4,5,6,7,8,9)$. However, many patients with lipodystrophy are not hypoleptinemic $(10,11)$. Therefore, there is a need to develop other therapies for treatment of hepatic steatosis in patients with lipodystrophies.

There is no proven effective therapy for hepatic steatosis (12). A variety of drugs have been investigated including ursodeoxycholic acid (13), insulin sensitizers (metformin and thiazolidinediones) $(14,15)$, vitamin $\mathrm{E}$ (14), betaine (16), and probucol (17). Thus far, only vitamin $\mathrm{E}$ has been shown to improve histology in patients with hepatic steatosis (14). However, these results have not yet been replicated and concerns related to an increase in mortality with vitamin E (18) have limited its use.

Bile acids play a role in the metabolism of both serum and hepatic triglyceride (TG). Cholic acid (CA) has been reported to reduce serum TG by as much as $29 \%$ in patients with hyperlipoproteinemia $(19,20)$. Recently, it has been noted that bile acids, which are the 
endogenous ligands of the farnesoid X receptor (FXR, NR1H4), activate transcription of several genes, particularly the atypical nuclear receptor small heterodimer partner, and thus can influence TG metabolism within hepatocytes (21). Both CA and chenodeoxycholic acid (CDCA), the endogenous primary bile acids, are potent ligands for FXR. Giving 0.5\% CA for 3 weeks reduced hepatic TG content by over $50 \%$ in KK- $A^{\mathrm{y}}$ mice (a model for diet-induced hypertriglyceridemia) fed chow or high-fat diet (22). In addition, activation of FXR was shown to robustly attenuate liver steatosis in leptin-receptor-mutated Zucker $f a / f a$ rats (a genetic model of insulin resistance and obesity-driven liver injury) (23). Therefore, FXR agonists may be beneficial for treating hepatic steatosis; however, there are no previous studies assessing their efficacy for reducing liver TG content in humans.

Thus, we designed a randomized, double-blind, placebo-controlled, crossover study to evaluate the efficacy and safety of CA therapy in treating hepatic steatosis in patients with lipodystrophy.

\section{Materials and methods}

\section{Setting and participants}

All patients were evaluated at the Clinical and Translational Research Center (CTRC) at UT Southwestern Medical Center (Dallas, Texas, USA). A written informed consent was obtained from all participants, and the study was approved by the Institutional Review Board of UT Southwestern. Thirty-seven patients with a clinical diagnosis of genetic or acquired autoimmune lipodystrophy (not HIV-associated) underwent screening with ${ }^{1} \mathrm{H}$ magnetic resonance spectroscopy (MRS) for liver fat. Ten subjects did not qualify after screening (eight had low levels of liver fat, one was too obese for the magnetic resonance imaging machine, one had a history of alcohol use), eight subjects lost interest, and one could not be contacted.

Inclusion criteria for the trial were as follows: patients with lipodystrophy as diagnosed by clinical criteria, hepatic steatosis ( $>5.6 \%$ hepatic TG content) as demonstrated by ${ }^{1} \mathrm{H}$ MRS, age $10-70$ years, and alcohol intake of $<40 \mathrm{~g} /$ week. Patients with the following were excluded: other liver diseases such as chronic viral hepatitis, autoimmune hepatitis, primary biliary cirrhosis, biliary obstruction, Wilson's disease, hemochromatosis, or $\alpha$-1-antitrypsin deficiency; treatment with drugs associated with steatohepatitis: corticosteroids, high-dose estrogens, methotrexate, amiodarone, calcium channel blockers, sulfasalazine, naproxen, or oxacillin in the 6 months before the study; decompensated liver disease; hepatocellular carcinoma; congestive heart failure, cerebrovascular disease, respiratory failure, renal failure (serum creatinine $>2 \mathrm{mg} / \mathrm{dl}$ ), acute pancreatitis, organ transplantation, serious psychiatric disease, and malignancy; acute medical illnesses; known HIV infection; current substance abuse; pregnant or lactating women; hematocrit of $<30 \%$; weight loss during the past 3 months; and hypersensitivity or intolerance to $\mathrm{CA}$ or any components of its formulation. Additional exclusion criteria included the use of drugs that can potentially decrease hepatic steatosis: ursodeoxycholic acid, highdose vitamin E, betaine, acetylcysteine, and choline. Thiazolidinediones were allowed if the dose had been stable for three months before screening.

\section{Design overview, randomization, and interventions}

This study was a randomized, double-blind, placebocontrolled, crossover trial (Fig. 1). Patients underwent a screening evaluation to determine their eligibility for the trial. For those who were found to be eligible, they continued their usual diet and other lifestyle measures without changing any medications for 1 month in order to establish a baseline state.

All patients were studied during three hospitalizations, each lasting for 3 days, and two outpatient visits (Fig. 1). One month after screening, patients were hospitalized to the CTRC for a period of 3 days, i.e. the baseline visit. Fasting blood samples were obtained on three consecutive days during the inpatient evaluation, and the average of the three measurements was used

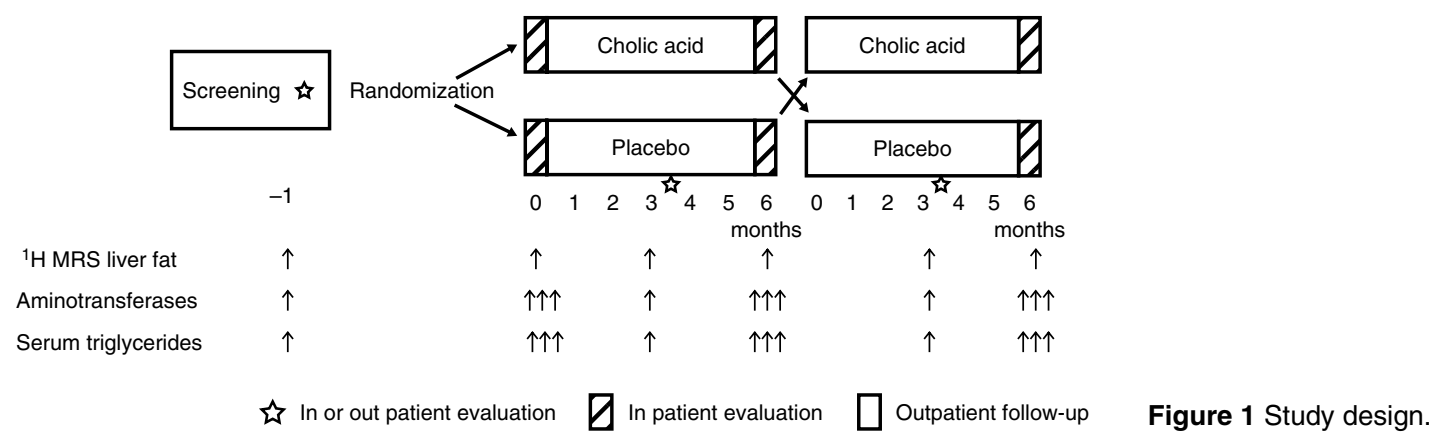

www.eje-online.org 
for data analysis. All patients underwent ${ }^{1} \mathrm{H}$ MRS to determine liver fat during this hospitalization. At 6 and 12 months, patients were again admitted for three consecutive days; during these visits, all the studies mentioned in the baseline visit were repeated. The patients returned at 3 and 9 months for fasting blood samples and liver ${ }^{1} \mathrm{H}$ MRS during outpatient visits.

Following the baseline hospitalization, the patients received $\mathrm{CA}$ or an identical placebo in the dose of $15 \mathrm{mg} / \mathrm{kg}$ per day (divided twice daily) for a period of 6 months and then received the other treatment (CA or placebo) for the next 6 months. The maximum dose of CA was $1500 \mathrm{mg} /$ day. CA and matched placebo were supplied by Global Strategic Connections, LLC (Troy, MI, USA), in $250 \mathrm{mg}$ capsules.

At each study visit, an inquiry was made about any side effects of medication, in particular, gastrointestinal side effects. Medication compliance was assessed by counting the remaining number of pills at the completion of each study period. If a patient was unable to tolerate the full dose, the dose could be reduced by the investigators. Patients were asked to keep doses of their other medications constant for the duration of the study.

\section{Outcomes}

The ${ }^{1} \mathrm{H}$ MRS studies were performed at least $4 \mathrm{~h}$ postprandially with the patients lying prone as described previously (24). Briefly, image-guided, proton-localized, MRS and high-resolution T1-weighted imaging were performed on a $1.5 \mathrm{~T}$ Gyroscan Intera whole-body system (Philips Medical Systems, Best, The Netherlands) with the following parameters: repetition time of $3 \mathrm{~s}$, spin echo time of $25 \mathrm{~ms}$, and 1024 data points over $1000 \mathrm{kHz}$ spectral width. Volume of interest (voxel $30 \mathrm{~mm}^{3}$ ) was selected in the upper right hepatic lobe, taking care to avoid vascular structures. Spectra were processed and resonances quantified using a standard analysis package (NUTS; ACORNNMR, Fremont, CA, USA). The hepatic TG content was expressed as the ratio of fat and water resonance peaks.

Blood was obtained after overnight (12 h) fast daily for chemistry profile (SMA-25) and lipoprotein levels while the patients were admitted. Serum chemistry profile including the aminotransferases, lipoproteins, gammaglutamyl transpeptidase (GGT), electrolytes, etc were measured by autoanalyzer (Quest Diagnostics, Irving, TX, USA). HbA1c levels were measured by an immunoturbidimetric colorimetric assay (Quest Diagnostics).

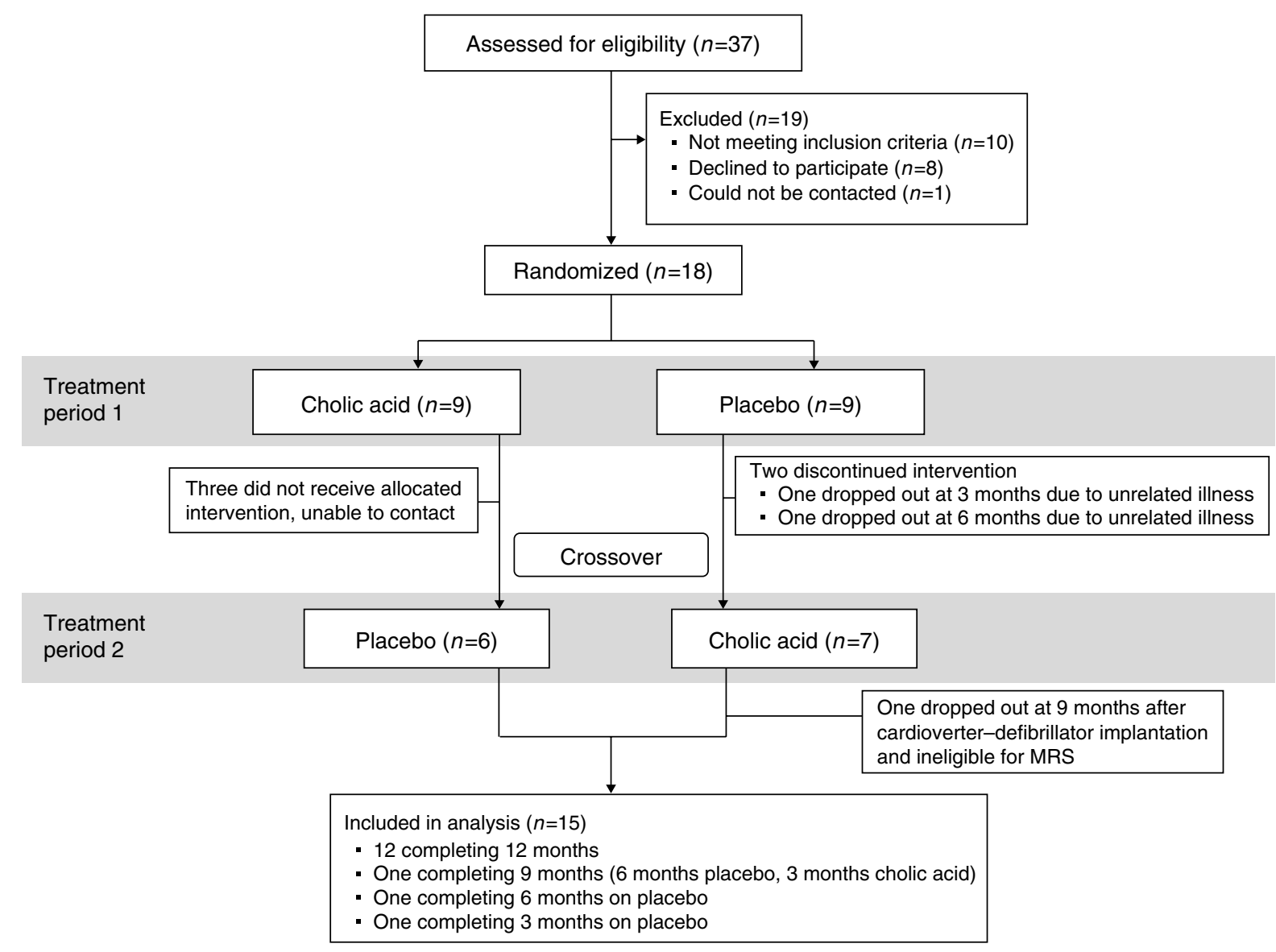

Figure 2 CONSORT 2010 flow diagram. 
Primary and secondary endpoint variables The primary end point variable was reduction in the liver TG content as measured by ${ }^{1} \mathrm{H}$ MRS. Reductions in the levels of serum alanine and aspartate aminotransferases (ALT and AST), GGT, and TG were secondary end point variables of the study.

\section{Statistical analysis}

We determined that a sample of 12 patients completing the 12-month crossover study would provide a power of 0.80 at an $\alpha$ of 0.05 to detect an absolute treatment difference in hepatic fat content of $3.5 \%$ with the s.D. of the difference of $4.0 \%$. We therefore planned to enroll at least 16 subjects assuming a maximum $30 \%$ rate of loss to follow-up.

A block randomization with block size of two was generated using SAS version 9.2 (SAS Institute, Cary, NC, USA). At the beginning of the study, a randomized treatment sequence was prepared by the study statistician who sent it directly to the investigative pharmacy. The pharmacist assigned participants to the interventions according to the treatment sequence. Patients were recruited by the study personnel. All participants and study personnel and those evaluating outcomes (e.g. ${ }^{1} \mathrm{H}$ MRS results) were blinded. Only the pharmacist was aware of the intervention sequence. The code was broken upon study completion.

All data on patients who had at least one 3-month measurement of hepatic TG content during the placebo or CA phase were included in the analysis $(n=15)$. For continuous outcome variables, statistical analysis of this two-phase crossover study was performed using mixed linear model repeated measures analysis with the study subject modeled as a random effect. The mixed-effects analysis was also used to assess a possible treatment sequence effect. All hypothesis tests were two sided and a $P$ value $<0.05$ was considered statistically significant. Results are reported as median and interquartile range. Statistical analyses were conducted using SAS.

\section{Results}

\section{Patients}

Recruitment began in December 2006, and the last patient finished the 12-month follow-up visit in April 2011. Eighteen patients were enrolled in the study and 12 of them completed both the CA and the placebo phases, whereas an additional three patients had 3-month data (Fig. 2). The six dropouts included three who were unable to be contacted, two who had hospitalizations and medication changes for unrelated illnesses, and one who had an implantable cardioverterdefibrillator placed for pre-existing cardiomyopathy due to which MRS could not be performed.
Table 1 Characteristics of all patients enrolled in the study. Values are given as mean (S.D.) unless otherwise noted.

\begin{tabular}{|c|c|c|}
\hline & $\begin{array}{l}\text { All enrolled } \\
\quad(n=18)\end{array}$ & Min-max \\
\hline Age (years) & $46.0(15.3)$ & $17-70$ \\
\hline $\mathrm{BMI}\left(\mathrm{kg} / \mathrm{m}^{2}\right)$ & $30(6)$ & $22-44$ \\
\hline Male:female & $7: 11$ & \\
\hline Diabetes & $67 \%$ & \\
\hline Hypertension & $50 \%$ & \\
\hline Dyslipidemia & $100 \%$ & \\
\hline Hepatic TG (\%) & $23.89^{\mathrm{a}}(13.4)$ & $6.1-60.3$ \\
\hline Weight (kg) & $80.7(16)$ & $56.0-109.0$ \\
\hline Total cholesterol (mg/dl) & 208.4 (64.9) & $116.0-355.0$ \\
\hline HDL-C $(\mathrm{mg} / \mathrm{dl})$ & $33.0(7.4)$ & $18.0-51.7$ \\
\hline $\mathrm{TG}(\mathrm{mg} / \mathrm{dl})$ & $389^{\mathrm{a}}$ & $155-3455$ \\
\hline $\mathrm{HbA1c}(\%)$ & $6.8(1.3)$ & $5.3-9.1$ \\
\hline Glucose $(\mathrm{mg} / \mathrm{dl})$ & $125.6(33.5)$ & 80-199 \\
\hline AST (U/l) & $29.4(13.2)$ & $12.0-55.0$ \\
\hline $\operatorname{ALT}(U / I)$ & $38.5(35.0)$ & $11.0-168.0$ \\
\hline GGT (U/I) & $35.4(16.7)$ & $16.0-72.0$ \\
\hline \multicolumn{3}{|l|}{ Lipid-lowering agents $(n)$} \\
\hline Statins & 7 & \\
\hline Fibrates & 7 & \\
\hline Fish oil & 7 & \\
\hline Ezetimibe & 3 & \\
\hline Niacin & 1 & \\
\hline \multicolumn{3}{|l|}{ Diabetes medications $(n)$} \\
\hline Metformin & 10 & \\
\hline Insulin & 7 & \\
\hline Sulfonylurea & 5 & \\
\hline Thiazolidinediones & 2 & \\
\hline GLP1 agonist & 2 & \\
\hline DPP-4 inhibitor & 1 & \\
\hline
\end{tabular}

TG, triglycerides; HDL-C, HDL cholesterol; ALT, alanine aminotransferase; AST, aspartate aminotransferase; GGT, gamma-glutamyl transpeptidase. GLP, glucagon-like peptide; DPP, dipeptidyl peptidase.

aMedian.

Table 1 describes the baseline characteristics of all patients enrolled in the study. At screening, the mean (S.D.) hepatic TG content was $23.9 \%$ (13.4\%), and the range was $6.1-60.3 \%$. Serum ALT concentration ranged from 11 to $168 \mathrm{U} / \mathrm{l}$; AST ranged from 12 to $55 \mathrm{U} / \mathrm{l}$; GGT ranged from 16 to $72 \mathrm{U} / \mathrm{l}$; and serum TG concentration ranged from 155 to $3455 \mathrm{mg} / \mathrm{dl}$. Twelve patients had a previous diagnosis of diabetes mellitus.

Nine patients had familial partial lipodystrophy of the Dunnigan variety (FPLD) due to mutations in the lamin A/C (LMNA) gene. Eight patients had other types of familial partial lipodystrophy. One patient had acquired generalized lipodystrophy.

\section{Primary and secondary end points}

The sequence in which the patients received CA or placebo had no effect on the results. Compared with placebo, CA therapy did not result in any significant reduction in hepatic TG concentration (geometric mean difference, $13.8 \%$; $95 \%$ CI -19.7 to $61.1 \%$ ). Similarly, there was no significant change in serum TG levels (11.4\%; $95 \%$ CI -17.7 to 50.8\%). Individual responses for hepatic TG concentration and serum TG levels are 

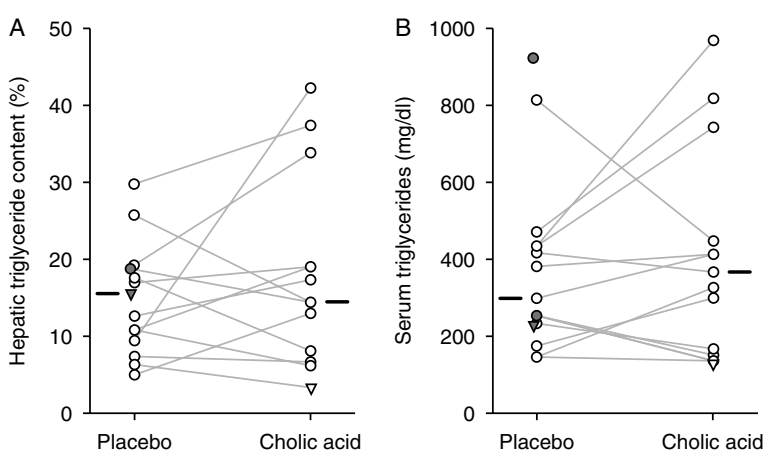

Figure 3 Hepatic triglyceride content $(A)$ and serum triglyceride levels (B) during the study. Connected open circles represent the 12 subjects who completed both the 6-month study periods. For three subjects with incomplete data, filled symbols represent subjects with placebo data only; inverted triangles represent 3-month data. Median values for each phase are shown as horizontal bars.

shown in Fig. 3 and overall results are reported in Table 2. CA therapy did not lower ALT $(-3.0 \%$; 95\% CI -24.3 to $24.2 \%)$, AST $(2.5 \% ; 95 \%$ CI -17.6 to $27.7 \%$ ), or GGT (1.6\%; $95 \%$ CI -18.0 to $26.0 \%$ ) levels. Mean difference in HbA1c was $0.41 \%$ (95\% CI - 0.23 to $1.05 \%)$; however, it was not statistically significant $(P=0.18)$. Absolute difference in weight was $-0.23 \mathrm{~kg}$ (95\% CI -2.02 to $1.56 \mathrm{~kg}$ ) for CA relative to placebo; however, it was also not statistically significant.

\section{Adverse events}

CA was well tolerated except in two patients who developed diarrhea and excessive flatus while taking CA. Their symptoms resolved after reducing the dosage of $\mathrm{CA}$ to $5-10 \mathrm{mg} / \mathrm{kg}$ per day. Three other patients reported mild diarrhea, which subsided within 1-2 weeks without any dose adjustment.

Four patients had adverse events during the trial. One patient developed gastroenteritis requiring i.v. fluids. Two patients developed flu-like symptoms with vomiting and diarrhea and also required i.v. fluids for volume depletion. One patient with multiple co-morbidities had four hospitalizations for fluid accumulation due to heart failure, chronic obstructive pulmonary disease, and pneumonia. All these adverse events occurred while the patients were taking placebo.

\section{Discussion}

We hypothesized that CA would improve hepatic TG content in humans based on the report of $>50 \%$ reduction in hepatic TG content in mice upon feeding $0.5 \%$ CA for 3 weeks (22). CA therapy restored liver morphology to normal with lower levels of unstained inclusions on hematoxylin and eosin staining and less accumulation of neutral lipids on Oil Red $\mathrm{O}$ staining. These effects seem to occur through SHP and liver X receptor-mediated downregulation of sterol regulatory element binding protein 1c (SREBF1) expression (22). These findings were recently replicated in rats (25). However, we were unable to observe any significant improvement in hepatic steatosis with CA therapy in lipodystrophic patients with markedly elevated hepatic TG content.

Recent data support the activation of FXR, a nuclear hormone receptor regulated by bile acids, for treatment of hepatic steatosis (26). FXR-deficient mice exhibit a hepatic phenotype similar to steatohepatitis patients with significant hepatic TG accumulation, hepatic inflammation and injury, and development of hepatocellular carcinoma $(27,28)$. WAY-362450, a potent, selective, and orally active synthetic FXR agonist, has been shown to protect against hepatic steatosis in mice fed a methionine- and choline-deficient diet (29). This hepatoprotection by WAY-362450 is abolished in FXR-deficient mice, demonstrating the requirement for functional FXR (29).

FXR activation alters the expression of many genes involved in lipid metabolism. While apolipoprotein $\mathrm{C}-1$, apolipoprotein C-II, apolipoprotein C-IV, apolipoprotein

Table 2 Results of cholic acid vs placebo ${ }^{a}$

\begin{tabular}{|c|c|c|c|c|c|c|}
\hline \multirow[b]{2}{*}{ Measure } & \multirow[b]{2}{*}{ Baseline } & \multicolumn{2}{|c|}{ Cholic acid } & \multicolumn{2}{|c|}{ Placebo } & \multirow[b]{2}{*}{$P$ value } \\
\hline & & 3 months & 6 months & 3 months & 6 months & \\
\hline HbA1c (\%) & $6.4(5.6-7.4)$ & $6.2(5.8-7.1)$ & $7.0(5.4-8.3)$ & $6.7(5.8-7.7)$ & $6.6(5.6-7.6)$ & 0.18 \\
\hline Weight (kg) & 77 (67.1-90.9) & 77 (65.8-94.5) & 75 (66.2-89.6) & $80.4(68-91.1)$ & $76.9(65.7-84.5)$ & 0.77 \\
\hline Glucose (mg/dl) & $115(91-134)$ & 112 (99-152) & $122(87-152)$ & 105 (90-131) & 108 (92-140) & 0.91 \\
\hline TG (mg/dl) & 278 (238-489) & 314 (217-532) & $390(233-595)$ & $283(220-400)$ & 340 (233-433) & 0.45 \\
\hline $\begin{array}{l}\text { Total cholesterol } \\
(\mathrm{mg} / \mathrm{dl})\end{array}$ & $214(160-280)$ & $176(167-227)$ & $196(173-242)$ & $186(169-206)$ & $200(164-234)$ & 0.31 \\
\hline HDL-C (mg/dl) & $36(31.9-42)$ & $30(28-37)$ & $32.2(24.7-36)$ & $33(28.6-37)$ & 30.7 (24.7-37) & 0.72 \\
\hline AST (U/I) & $23(18-31)$ & $20(15-25)$ & $22(15.5-28.5)$ & $18(14-34)$ & $19(14.7-32.3)$ & 0.80 \\
\hline $\operatorname{ALT}(\mathrm{U} / \mathrm{I})$ & $26(17.7-39.3)$ & $25(18-29)$ & $25.1(18.9-48)$ & $24.5(18-49)$ & $22.8(19.7-37.3)$ & 0.79 \\
\hline GGT (U/I) & 26.7 (21.7-30.3) & $30(21-38)$ & $27.2(21.8-41.1)$ & $26(22-44)$ & $29.8(23-47.3)$ & 0.87 \\
\hline
\end{tabular}

TG, triglycerides; HDL-C, HDL cholesterol; ALT, alanine aminotransferase; AST, aspartate aminotransferase; GGT, gamma-glutamyl transpeptidase.

aValues are given as median (interquartile range) unless otherwise noted. 
E, fatty acid synthase, and peroxisome proliferatoractivated receptor $\alpha$ are upregulated, angiopoietin-like protein 3 (ANGPTL3), apolipoprotein A-1, apolipoprotein C-III, and SREBP1c $(22,30)$ are down regulated. All these changes may lead to reduction of hepatic steatosis and serum TG upon FXR activation.

Studies in FXR knockout mice show that FXR is involved in the regulation of insulin signaling pathways and appears to have a beneficial role in decreasing insulin resistance and gluconeogenesis, as well as in regulating TG, free fatty acid, and lipid levels $(28,31)$. This adds to the rationale for clinical testing of $\mathrm{CA}$ in subjects with chronic liver disease where insulin resistance is a major risk factor for progression to cirrhosis, e.g. nonalcoholic fatty liver disease and its more clinically significant subtype nonalcoholic steatohepatitis (26).

CA has been reported to reduce serum TG levels in patients with mild hypertriglyceridemia $(19,20)$. Administration of $15 \mathrm{mg} / \mathrm{kg}$ body weight per day of CA for 3 months decreased plasma TG in six out of eight patients with moderate hypertriglyceridemia. However, plasma TG levels (mean \pm s.e.m.) declined by only $16 \%$ from $283 \pm 27$ to $239 \pm 18 \mathrm{mg} / \mathrm{dl}(P<0.05)(20)$, and in the study subjects with type 2 a hyperlipoproteinemia, there was no change in plasma TG levels. Einarsson et al. (19) also reported a $29 \%$ reduction in serum TG from $411 \pm 180 \mathrm{mg} / \mathrm{dl}($ mean \pm s.D.) to $291 \pm 55 \mathrm{mg} / \mathrm{dl}$ after 2-3 weeks of therapy with $0.8-1.0 \mathrm{~g} \mathrm{CA}$. However, this study involved only five men with hypertriglyceridemia, and the results were not statistically significant. In addition, neither of these studies was a randomized, double-blind, placebo-controlled trial. More recently, Woollett et al. (32) administered CA (15 mg/kg per day) vs no bile acid supplement (control) to 12 healthy, normotriglyceridemic subjects who were being fed a controlled diet. They failed to find any lowering of plasma TG $(78.5 \pm 8.6$ vs $73.9 \pm 8.6 \mathrm{mg} / \mathrm{dl}$, NS). Interestingly, although most of our patients with lipodystrophies were hypertriglyceridemic, we did not observe any significant lowering of serum TG with CA therapy, compared with placebo therapy. Our results do not confirm the TG-lowering effects of $\mathrm{CA}$ that were previously reported.

Although CDCA is a more potent FXR agonist than CA and can also lower serum TG $(33,34,35,36)$, CA was chosen over CDCA because of better tolerance and less hepatotoxicity (37). CA has been used, without any side effects, since 1994 at the Cincinnati Children's Hospital Medical Center for the treatment of inborn errors of bile acid metabolism (38). In addition, CA has previously been studied at doses as high as $20 \mathrm{mg} / \mathrm{kg}$ per day in adults to dissolve gallstones (39), to treat mild hypertriglyceridemia $(19,20)$, to study bile acid kinetics $(40,41,42,43)$, and to assess cholesterol absorption $(32,44)$. The only adverse effect reported in these studies was mild diarrhea. In our study, no major adverse events were attributed to CA, although a few patients complained of diarrhea. Our results confirm that CA is not hepatotoxic and is overall well tolerated.

The major strength of this study is the robust study design. In view of the rare prevalence of lipodystrophies, we decided to use the randomized, double-blind, placebo-controlled, crossover design. This allowed us to achieve more power with fewer patients compared with the parallel design. We selected 6-month duration of treatment, which is long enough to detect effects of CA therapy on hepatic steatosis. Despite that, no effects of sequence in which the patients received $\mathrm{CA}$ or placebo therapy were observed. We also avoided using low dose of CA and selected to administer $15 \mathrm{mg} / \mathrm{kg}$ per day for a maximum of $1500 \mathrm{mg} /$ day.

Several possibilities could explain why CA failed to reduce hepatic TG content as measured by ${ }^{1} \mathrm{H}$ MRS. First, hepatic steatosis in lipodystrophy patients may have different pathophysiology (45) and may not involve downregulation of FXR and thus may not respond to CA therapy. Secondly, as we did not perform liver biopsies, it is possible that some histological improvements occurred but did not result in an overall reduction of hepatic TG content. Finally, CA may not be a potent enough FXR agonist and other more potent FXR agonists, such as obeticholic acid (Intercept Pharmaceuticals, New York, NY, USA), which is 100 times more potent than CDCA, GW4064 (GlaxoSmithKline), MFA-1 (Merck), and fexaramine, may prove to be efficacious in treating hepatic steatosis (46). In conclusion, CA was well tolerated but did not reduce hepatic TG content in patients with lipodystrophy.

\section{Declaration of interest}

The authors declare that there is no conflict of interest that could be perceived as prejudicing the impartiality of the research reported.

\section{Funding}

This study is supported by research grant R01-FD003085 by the Food and Drug Administration and M01-RR00633 and UL1-RR-024982 from the National Institutes of Health and from the Southwest Medical Foundation.

\section{Acknowledgements}

The authors thank Sarah Masood and Rashmin Asher for technical assistance. They also thank Claudia Quittner for help in conducting this clinical trial.

\section{References}

1 Garg A. Acquired and genetic lipodystrophies. New England Journal of Medicine $2004350 \quad 1220-1234$. (doi:10.1056/ NEJMra025261)

2 Misra A \& Garg A. Clinical features and metabolic derangements in acquired generalized lipodystrophy: case reports and review of the literature. Medicine $2003 \mathbf{8 2}$ 129-146. (doi:10.1097/ 00005792-200303000-00007) 
3 Cauble MS, Gilroy R, Sorrell MF, Mailliard ME, Sudan DL, Anderson JC, Wisecarver JL, Balakrishnan S \& Larsen JL. Lipoatrophic diabetes and end-stage liver disease secondary to nonalcoholic steatohepatitis with recurrence after liver transplantation. Transplantation 200171 892-895. (doi:10.1097/ 00007890-200104150-00012)

4 Oral EA, Simha V, Ruiz E, Andewelt A, Premkumar A, Snell P, Wagner AJ, DePaoli AM, Reitman ML, Taylor SI et al. Leptinreplacement therapy for lipodystrophy. New England Journal of Medicine 2002346 570-578. (doi:10.1056/NEJMoa012437)

5 Simha V, Szczepaniak LS, Wagner AJ, DePaoli AM \& Garg A. Effect of leptin replacement on intrahepatic and intramyocellular lipid content in patients with generalized lipodystrophy. Diabetes Care 200326 30-35. (doi:10.2337/diacare.26.1.30)

6 Petersen KF, Oral EA, Dufour S, Befroy D, Ariyan C, Yu C, Cline GW, DePaoli AM, Taylor SI, Gorden P et al. Leptin reverses insulin resistance and hepatic steatosis in patients with severe lipodystrophy. Journal of Clinical Investigation 2002109 1345-1350.

7 Javor ED, Cochran EK, Musso C, Young JR, Depaoli AM \& Gorden P. Long-term efficacy of leptin replacement in patients with generalized lipodystrophy. Diabetes $2005 \mathbf{5 4} 1994-2002$. (doi:10.2337/diabetes.54.7.1994)

8 Javor ED, Ghany MG, Cochran EK, Oral EA, DePaoli AM, Premkumar A, Kleiner DE \& Gorden P. Leptin reverses nonalcoholic steatohepatitis in patients with severe lipodystrophy. Hepatology 200541 753-760. (doi:10.1002/hep.20672)

9 Simha V, Subramanyam L, Szczepaniak L, Quittner C, Adams-Huet B, Snell P \& Garg A. Comparison of efficacy and safety of leptin replacement therapy in moderately and severely hypoleptinemic patients with familial partial lipodystrophy of the Dunnigan variety. Journal of Clinical Endocrinology and Metabolism 201197 785-792. (doi:10.1210/jc.2011-2229)

10 Haque WA, Shimomura I, Matsuzawa Y \& Garg A. Serum adiponectin and leptin levels in patients with lipodystrophies. Journal of Clinical Endocrinology and Metabolism 2002872395. (doi:10.1210/jc.87.5.2395)

11 Wong SP, Huda M, English P, Bargiotta A, Wilding JP, Johnson A, Corrall R \& Pinkney JH. Adipokines and the insulin resistance syndrome in familial partial lipodystrophy caused by a mutation in lamin A/C. Diabetologia 200548 2641-2649. (doi:10.1007/ s00125-005-0038-x)

12 Nguyen TA \& Sanyal AJ. Pathophysiology guided treatment of nonalcoholic steatohepatitis. Journal of Gastroenterology and Hepatology 201227 (Suppl 2) 58-64. (doi:10.1111/j.14401746.2011.07018.x)

13 Leuschner UF, Lindenthal B, Herrmann G, Arnold JC, Rossle M, Cordes HJ, Zeuzem S, Hein J \& Berg T. High-dose ursodeoxycholic acid therapy for nonalcoholic steatohepatitis: a double-blind, randomized, placebo-controlled trial. Hepatology 2010 52 472-479. (doi:10.1002/hep.23727)

14 Sanyal AJ, Chalasani N, Kowdley KV, McCullough A, Diehl AM, Bass NM, Neuschwander-Tetri BA, Lavine JE, Tonascia J, Unalp A et al. Pioglitazone, vitamin E, or placebo for nonalcoholic steatohepatitis. New England Journal of Medicine 2010 362 1675-1685. (doi:10.1056/NEJMoa0907929)

15 Angelico F, Burattin M, Alessandri C, Del Ben M \& Lirussi F. Drugs improving insulin resistance for non-alcoholic fatty liver disease and/or non-alcoholic steatohepatitis. Cochrane Database of Systematic Reviews 2007 (Article ID CD005166). (doi:10.1002/ 14651858.CD005166)

16 Abdelmalek MF, Sanderson SO, Angulo P, Soldevila-Pico C, Liu C, Peter J, Keach J, Cave M, Chen T, McClain CJ et al. Betaine for nonalcoholic fatty liver disease: results of a randomized placebocontrolled trial. Hepatology 200950 1818-1826. (doi:10.1002/ hep.23239)

17 Merat S, Malekzadeh R, Sohrabi MR, Sotoudeh M, Rakhshani N, Sohrabpour AA \& Naserimoghadam S. Probucol in the treatment of non-alcoholic steatohepatitis: a double-blind randomized controlled study. Journal of Hepatology 200338 414-418. (doi:10.1016/S0168-8278(02)00441-5)
18 Miller ER III, Pastor-Barriuso R, Dalal D, Riemersma RA, Appel LJ \& Guallar E. Meta-analysis: high-dosage vitamin E supplementation may increase all-cause mortality. Annals of Internal Medicine $200514237-46$.

19 Einarsson K, Hellstrom K \& Kallner M. Effect of cholic acid feeding on bile acid kinetics and neutral fecal steroid excretion in hyperlipoproteinemia (types II and IV). Metabolism 197423 863-873. (doi:10.1016/0026-0495(74)90120-6)

20 Angelin B \& Leijd B. Effects of cholic acid on the metabolism of endogenous plasma triglyceride and on biliary lipid composition in hyperlipoproteinemia. Journal of Lipid Research 198021 1-9.

21 Fujino T, Une M, Imanaka T, Inoue K \& Nishimaki-Mogami T. Structure-activity relationship of bile acids and bile acid analogs in regard to FXR activation. Journal of Lipid Research $2004 \mathbf{4 5}$ 132-138. (doi:10.1194/jlr.M300215-JLR200)

22 Watanabe M, Houten SM, Wang L, Moschetta A, Mangelsdorf DJ, Heyman RA, Moore DD \& Auwerx J. Bile acids lower triglyceride levels via a pathway involving FXR, SHP, and SREBP-1c. Journal of Clinical Investigation 2004113 1408-1418.

23 Cipriani S, Mencarelli A, Palladino G \& Fiorucci S. FXR activation reverses insulin resistance and lipid abnormalities and protects against liver steatosis in Zucker (fa/fa) obese rats. Journal of Lipid Research 201051 771-784. (doi:10.1194/jlr.M001602)

24 Szczepaniak LS, Nurenberg P, Leonard D, Browning JD, Reingold JS, Grundy S, Hobbs HH \& Dobbins RL. Magnetic resonance spectroscopy to measure hepatic triglyceride content: prevalence of hepatic steatosis in the general population. American Journal of Physiology. Endocrinology and Metabolism 2005288 E462-E468. (doi:10.1152/ajpendo.00064.2004)

25 Gabbi C, Bertolotti M, Anzivino C, Macchioni D, Del Puppo M, Ricchi M, Carubbi F, Tagliafico E, Romagnoli D, Odoardi MR et al. Effects of bile duct ligation and cholic acid treatment on fatty liver in two rat models of non-alcoholic fatty liver disease. Digestive and Liver Disease 201244 1018-1026.

26 Adorini L, Pruzanski M \& Shapiro D. Farnesoid X receptor targeting to treat nonalcoholic steatohepatitis. Drug Discovery Today 201217 988-997. (doi:10.1016/j.drudis.2012.05.012)

27 Zhang Y \& Edwards PA. FXR signaling in metabolic disease. FEBS Letters 2008582 10-18. (doi:10.1016/j.febslet.2007.11.015)

28 Sinal CJ, Tohkin M, Miyata M, Ward JM, Lambert G \& Gonzalez FJ. Targeted disruption of the nuclear receptor FXR/BAR impairs bile acid and lipid homeostasis. Cell 2000102 731-744. (doi:10.1016/S0092-8674(00)00062-3)

29 Zhang S, Wang J, Liu Q \& Harnish DC. Farnesoid X receptor agonist WAY-362450 attenuates liver inflammation and fibrosis in murine model of non-alcoholic steatohepatitis. Journal of Hepatology 200951 380-388. (doi:10.1016/j.jhep. 2009.03.025)

30 Kast HR, Nguyen CM, Sinal CJ, Jones SA, Laffitte BA, Reue K, Gonzalez FJ, Willson TM \& Edwards PA. Farnesoid X-activated receptor induces apolipoprotein C-II transcription: a molecular mechanism linking plasma triglyceride levels to bile acids. Molecular Endocrinology 200115 1720-1728. (doi:10.1210/ me.15.10.1720)

31 Duran-Sandoval D, Cariou B, Percevault F, Hennuyer N, Grefhorst A, van Dijk TH, Gonzalez FJ, Fruchart JC, Kuipers F \& Staels B. The farnesoid X receptor modulates hepatic carbohydrate metabolism during the fasting-refeeding transition. Journal of Biological Chemistry 2005280 29971-29979. (doi:10.1074/ jbc.M501931200)

32 Woollett LA, Buckley DD, Yao L, Jones PJ, Granholm NA, Tolley EA, Tso P \& Heubi JE. Cholic acid supplementation enhances cholesterol absorption in humans. Gastroenterology 2004126 724-731. (doi:10.1053/j.gastro.2003.11.058)

33 Carulli N, Ponz de Leon M, Podda M, Zuin M, Strata A, Frigerio G \& Digrisolo A. Chenodeoxycholic acid and ursodeoxycholic acid effects in endogenous hypertriglyceridemias. A controlled doubleblind trial. Journal of Clinical Pharmacology 198121 436-442. (doi:10.1002/j.1552-4604.1981.tb01746.x) 
34 Camarri E, Marcolongo R \& Fici F. Hypotriglyceridemic effect of chenodeoxycholic acid after a short time of administration. International Journal of Clinical Pharmacology and Biopharmacy $197816527-528$.

35 Camarri E, Fici F \& Marcolongo R. Influence of chenodeoxycholic acid on serum triglycerides in patients with primary hypertriglyceridemia. International Journal of Clinical Pharmacology and Biopharmacy 197816 523-526.

36 Bateson MC, Maclean D, Evans JR \& Bouchier IA. Chenodeoxycholic acid therapy for hypertriglyceridaemia in men. British Journal of Clinical Pharmacology 19785 249-254. (doi:10.1111/ j.1365-2125.1978.tb01632.x)

37 Schoenfield LJ \& Lachin JM. Chenodiol (chenodeoxycholic acid) for dissolution of gallstones: the National Cooperative Gallstone Study. A controlled trial of efficacy and safety. Annals of Internal Medicine $198195257-282$.

38 Setchell KD \& Heubi JE. Defects in bile acid biosynthesis - diagnosis and treatment. Journal of Pediatric Gastroenterology and Nutrition 200643 (Suppl 1) S17-S22. (doi:10.1097/01.mpg.0000226 386.79483.7b)

39 Adler RD, Bennion LJ, Duane WC \& Grundy SM. Effects of low dose chenodeoxycholic acid feeding on biliary lipid metabolism. Gastroenterology $1975 \mathbf{6 8} 326-334$.

40 Thistle JL \& Hofmann AF. Efficacy and specificity of chenodeoxycholic acid therapy for dissolving gallstones. New England Journal of Medicine $1973 \mathbf{2 8 9}$ 655-659. (doi:10.1056/NEJM1973092 72891303)
41 Toouli J, Jablonski P \& Watts JM. Gallstone dissolution in man using cholic acid and lecithin. Lancet 19752 1124-1126. (doi:10.1016/S0140-6736(75)91008-9)

42 LaRusso NF, Hoffman NE, Hofmann AF, Northfield TC \& Thistle JL. Effect of primary bile acid ingestion on bile acid metabolism and biliary lipid secretion in gallstone patients. Gastroenterology 1975 69 1301-1314.

43 Thistle JL \& Schoenfield LJ. Induced alterations in composition of bile of persons having cholelithiasis. Gastroenterology 1971 61 488-496.

44 Sama C \& LaRusso NF. Effect of deoxycholic, chenodeoxycholic, and cholic acids on intestinal absorption of cholesterol in humans. Mayo Clinic Proceedings 198257 44-50.

45 Agarwal AK, Sukumaran S, Cortes VA, Tunison K, Mizrachi D, Sankella S, Gerard RD, Horton JD \& Garg A. Human 1-acylglycerol-3-phosphate $O$-acyltransferase isoforms 1 and 2: biochemical characterization and inability to rescue hepatic steatosis in Agpat2(-/-) gene lipodystrophic mice. Journal of Biological Chemistry 2011286 37676-37691. (doi:10.1074/jbc. M111.250449)

46 Lindor KD. Farnesoid X receptor agonists for primary biliary cirrhosis. Current Opinion in Gastroenterology 201127 285-288. (doi:10.1097/MOG.0b013e32834452c8)

Received 2 November 2012

Revised version received 8 January 2013

Accepted 27 February 2013 